This is the peer reviewed version of the following article: [Ghadakzadeh, S., Mekhail, M., Aoude, A., Hamdy, R., and Tabrizian, M. (2016). Small Players Ruling the Hard Game: siRNA in Bone Regeneration. Journal of Bone and Mineral Research 31, 475-487.] 


\title{
Small Players Ruling the Hard Game: siRNA in Bone Regeneration
}

\author{
Saber Ghadakzadeh, ${ }^{1,2}$ Mina Mekhail, ${ }^{2}$ Ahmed Aoude, ${ }^{2}$ Reggie Hamdy, ${ }^{1,2}$ and Maryam Tabrizian ${ }^{3}$ \\ ${ }^{1}$ Experimental Surgery, Department of Surgery, Faculty of Medicine, McGill University, Montreal, Canada \\ ${ }^{2}$ Division of Orthopaedic Surgery, Shriners Hospital for Children, McGill University, Montreal, Canada \\ ${ }^{3}$ Department of Biomedical Engineering, McGill University, Montreal, Canada
}

\begin{abstract}
Silencing gene expression through a sequence-specific manner can be achieved by small interfering RNAs (siRNAs). The discovery of this process has opened the doors to the development of siRNA therapeutics. Although several preclinical and clinical studies have shown great promise in the treatment of neurological disorders, cancers, dominant disorders, and viral infections with siRNA, siRNA therapy is still gaining ground in musculoskeletal tissue repair and bone regeneration. Here we present a comprehensive review of the literature to summarize different siRNA delivery strategies utilized to enhance bone regeneration. With advancement in understanding the targetable biological pathways involved in bone regeneration and also the rapid progress in siRNA technologies, application of siRNA for bone regeneration has great therapeutic potential. High rates of musculoskeletal injuries and diseases, and their inevitable consequences, impose a huge financial burden on individuals and healthcare systems worldwide. ๑ 2016 American Society for Bone and Mineral Research.
\end{abstract}

KEY WORDS: SMALL INTERFERING RNA; OLIGOTHERAPEUTIC; GENE THERAPY; DELIVERY SYSTEMS; FRACTURE HEALING; NONUNION BONE HEALING; BONE TISSUE ENGINEERING

\section{Introduction}

$\mathrm{B}^{\mathrm{s}}$ ne retains the capacity to employ all of the essential signaling cascades present during organogenesis, on the occasion of an injury repair throughout life. ${ }^{(1)}$ Bone healing and fracture repair occur via an orchestrated sequence of overlapping molecular and cellular events ${ }^{(2)}$ (Fig. 1A). Owing to advancements in molecular and physiological sciences, there is a growing understanding of the cellular events and underlying mechanisms involved in healthy fracture healing and natural bone regeneration. ${ }^{(3,4)}$ However, in spite of bone's natural ability to regenerate following an injury, large amounts of bone loss due to trauma, tumor excision, developmental anomalies, or infections do not heal on their own and require therapeutic intervention $^{(5)}$ (Fig. 1B). These "critical size defects," in which bone regeneration fails to occur, present major clinical complications in reconstructive orthopedic and craniofacial surgery. ${ }^{(6)}$

Surgical reconstructive approaches to these defects include llizarov, Masquelet, and bone graft techniques ${ }^{(7)}$ (Fig. 1C). However, the most widely used surgical technique, and the gold standard for treating such conditions, is autologous bone grafting. ${ }^{(7,8)}$ In spite of encouraging results, there are morbidities associated with this technique due to postoperative infections and longer hospitalization time. Moreover, the amount of available autologous bone from a patient is limited, and two invasive surgical procedures are needed for bone extraction (usually from the iliac crest) and grafting at the site of injury. $(6,8,9)$

The field of tissue engineering offers a promising alternative to the use of autologous bone grafts. ${ }^{(10,11)}$ The main principle behind a traditional tissue engineering approach involves the use of three components (ie, triangular concept): a scaffolding biomaterial, growth factors (both osteoinductive and angiogenic), and cells with potential osteoblastic fate. ${ }^{(3,6)}$ Biomaterials are also utilized in the design of drug delivery systems (DDSs) that can provide a controlled release of growth factors at the site of injury. The major advantage of providing a controlled release is the ability to reduce the concentrations of growth factors needed to induce a therapeutic effect, which reduces overall cost and eliminates any unwanted side effects associated with high doses.

Growth factors that stimulate one or several phases of bone formation have recently been identified and studied for specific clinical applications such as fracture repair, long bone nonunions, spinal fusions, and periodontal and dental procedures. ${ }^{(6)}$ The most widely studied growth factors for bone tissue engineering are bone morphogenetic proteins (BMPs). ${ }^{(12,13)}$ In skeletal tissue, BMPs are secreted by various cells types involved in the healing process. Secreted BMPs interact with their specific surface receptors on target cells and initiate a cascade of intracellular signals, leading to osteoblastic downstream gene expression. Some types of BMPs (rhBMP2 and rhBMP7) are currently commercially available and have been used in clinical

Received in original form December 2, 2015; revised form February 2, 2016; accepted February 16, 2016. Accepted manuscript online February 17, 2016. Address correspondence to: Saber Ghadakzadeh, MD, MSc, Division of Orthopaedic Surgery, Shriners Hospital for Children, McGill University, 1003 boul. DécarieMontréal (Québec) H4A 0A9, Canada. E-mail: saber.ghadakzadeh@mail.mcgill.ca

Journal of Bone and Mineral Research, Vol. 31, No. 3, March 2016, pp 475-487

DOI: $10.1002 / j b m r .2816$

(C) 2016 American Society for Bone and Mineral Research 
A

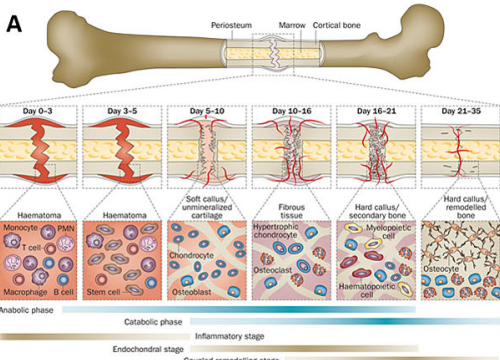

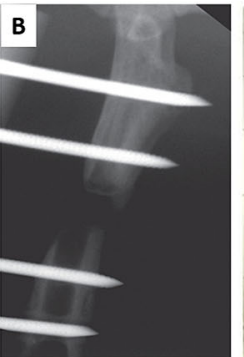
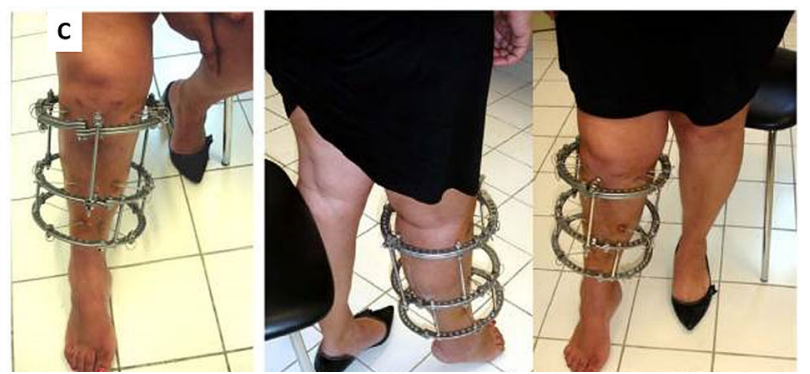

Fig. 1. (A) Schematic presentation of three main physiological stages of fracture healing (inflammatory stage, endochondral bone formation, and remodeling stages) in a mouse model with closed femur fracture and an intramedullary rod fixation. ${ }^{(4)}(B)$ Critical size defect in the rat femur. ${ }^{(26)}$ (C) Ilizarov technique for long bones. ${ }^{(121)}$

applications. ${ }^{(13-15)}$ However, because of their short half-life in vivo, and tendency to diffuse away from the site of application, doses thousands of times higher than physiological concentrations are needed to achieve a therapeutic effect. ${ }^{(16,17)}$ Aside from the enormous cost of such amounts of recombinant protein, they may cause serious safety issues for patients such as toxicity, heterotopic ossification, retrograde ejaculation, osteolysis, seroma/hematoma, infection, and dysphagia. ${ }^{(15,16,18,19)}$ Therefore, as mentioned previously, designing a DDS capable of providing a controlled release of BMPs is highly desirable.

In addition to BMPs, the effects of other agents such as synthetic peptides, ${ }^{(20)}$ small molecules (eg, phenamil, purmorphamine), ${ }^{(21)}$ or drugs (eg, statins, melatonin) on bone regeneration have been explored. ${ }^{(6,13,22,23)}$

Similar to the delivery of growth factors, gene therapy aims to deliver genetic material in order to induce and stimulate new bone formation at the site of bone defects. This could be achieved by introducing genes into bone tissue in an attempt to enhance the local expression of proteins capable of either reducing bone resorption or enhancing the infiltration and proliferation of osteoblast precursors and cell differentiation toward an osteogenic lineage. Gene therapy methods explored for bone tissue engineering include vector-mediated ex vivo and in vivo DNA transfection of the cells. A variety of vectors and genes have been extensively investigated for gene therapy in bone. A detailed description of such methods is beyond the scope of this review, but can be found in other topic-specific reviews. ${ }^{(24-26)}$

RNA interference (RNAi) is an innovative biological mechanism that reduces the gene expression, characteristically by destruction of the transcript product (ie, messenger RNA [mRNA]) via different known processes. Two types of small RNA are fundamental to RNAi: microRNA (miRNA) and small interfering RNA (siRNA). Natively expressed pri-mRNA molecules are short hairpin structures (about 61 nucleotides long) encoded by nuclear DNA. These molecules are further processed in the nucleus to form pre-miRNAs and then exported to the cytoplasm. Pre-miRNAs are identified by a protein complex called Dicer which cleaves them into shorter miRNAs with two strands of nonperfect complementarity. Double-stranded miRNA is detected by Argonaute 2 (AGO2) and integrated into the RNA-induced silencing complex (RISC). The passenger strand is discarded and the guide strand of miRNA guides this complex to bind the target mRNA with partial complementarity, leading to mRNA translation repression, degradation, or cleavage. ${ }^{(27,28)}$

Similarly, endogenous or exogenously introduced long double-stranded RNA (dsRNA) is also identified by Dicer, which cleaves the dsRNA into 20 to 25 nucleotide siRNAs, with perfect complementarity. ${ }^{(29,30)}$ A single strand of siRNA complexes with RISC and recognizes homologous mRNA substrates matched exactly with the siRNA sequence. The RISC-siRNA complex mediates the cleavage of the mRNA to smaller pieces. Subsequently, the accumulation of mRNA in the cytosol is reduced and this leads to a downregulation of the target gene expression. ${ }^{(31-34)}$ The simplified series of these events is shown schematically in Fig. 2. In addition to the naturally occurring intracellular miRNA and siRNA, the synthetic form of these molecules could be introduced into the cells exogenously. ${ }^{(35,36)}$ There are several excellent reviews on this topic that are suggested for further reading. ${ }^{(27,28,37-40)}$

Short hairpin RNA (shRNA) is synthesized intracellularly by the production of vector-mediated DNA. ${ }^{(41,42)}$ The structure of shRNA consists of two complementary 19-bp to 22-bp RNA sequences that are linked to each other by a noncomplementary sequence of 4 to 11 nucleotides, forming a short loop, similar to the hairpin structure present in the natural miRNA. ${ }^{(42)}$ Expression of shRNA is attained using plasmids delivered to cells by viral or bacterial vectors. ${ }^{(43)}$ In addition to the unfavorable type of vectors (ie, viral or bacterial) for future clinical applications, shRNA has been associated with a high risk of overexpression and toxicity in the cells. ${ }^{(44)}$

The silencing property of siRNAs was initially revealed by Fire and colleagues ${ }^{(45)}$ in 1998 and is continuously developing as an innovative approach to downregulate target gene expression. ${ }^{(46)}$ RNAi, particularly siRNAs, have been utilized as investigational tools to understand the biological role of specific genes by observing the consequences of knocking down that gene in vitro or in vivo. Similar to other tissues, several bonespecific pathways and genes have been elucidated using this technique. ${ }^{(47-71)}$

However, recent applications of siRNA have gone beyond investigatory studies and into the field of therapeutics. ${ }^{(72)}$ The ability to knock down any gene of interest by knowing the mRNA sequence alone provides an inexpensive and robust technique for treating a wide range of diseases. In the case of bone regeneration, siRNA that can knock down the expression of BMP inhibitors such as Noggin and Chordin has been widely explored as a means of enhancing bone formation. The major challenge, however, is the ability to deliver the siRNA into the cytoplasm of target cells and to promote the successful formation of the RISC complex. ${ }^{(73)}$ In order to overcome this issue, various DDSs have been investigated in order to preserve the siRNA in the extracellular environment, promote its uptake 


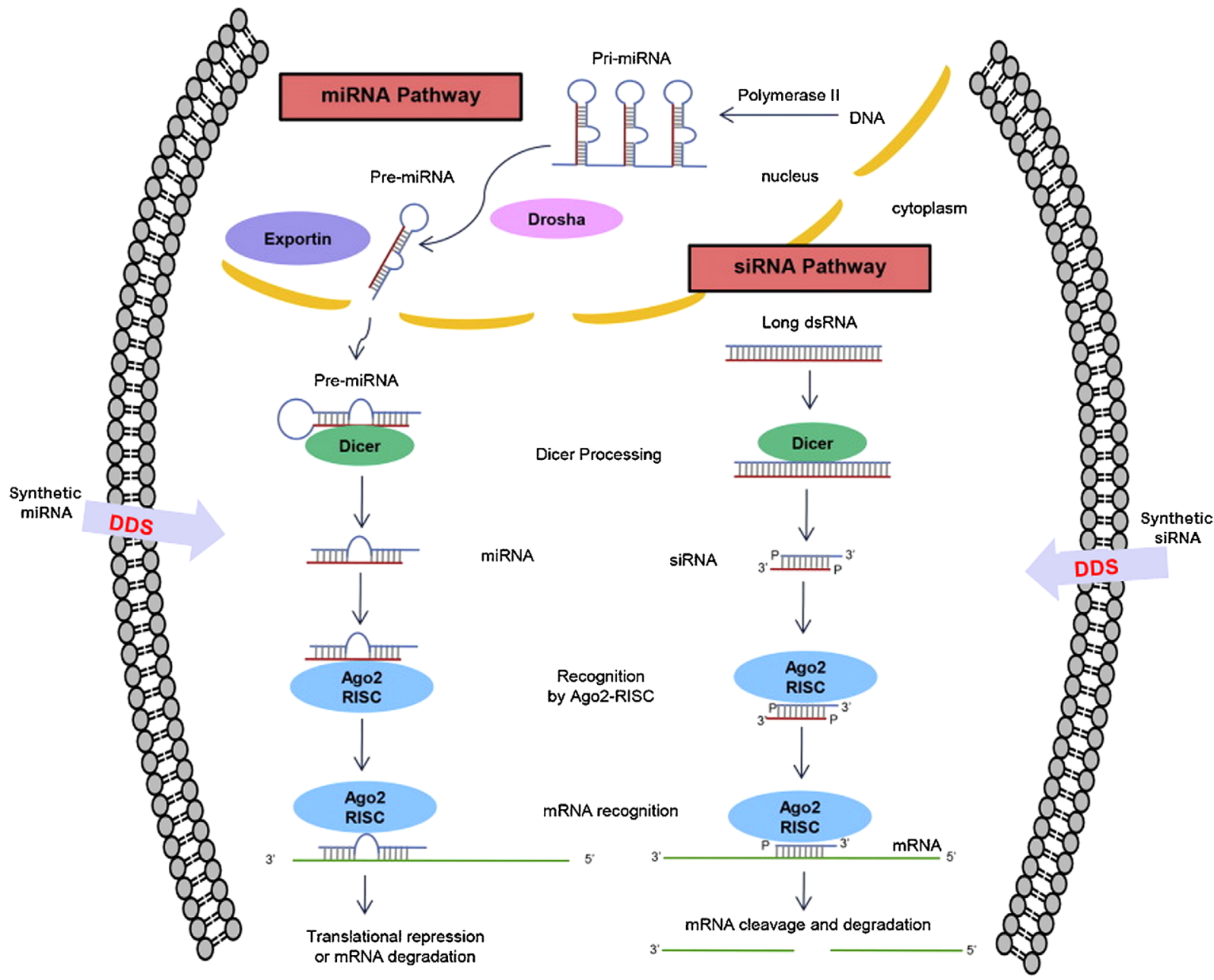

Fig. 2. Schematic mechanism of RNAi. ${ }^{(27)}$ siRNA: Transcribed or exogenously introduced long dsRNA is detected by a protein complex called Dicer, which cleaves it into multiple siRNAs then loaded into the RISC. One strand of siRNA is cleaved by AGO2, a component of RISC, the remaining strand (guide strand) guides the active RISC to recognize its target mRNA with exact complementarity. The RISC-siRNA complex mediates the cleavage and degradation of the mRNA and results in gene silencing. miRNA: Nuclear transcribed pri-miRNAs are cleaved by Drosha and form pre-miRNAs, which are later exported to the cytoplasm by Exportin. Pre-miRNA is detected and further processed by Dicer to miRNA, with two strands of imperfect complementarity. The miRNA is detected by AGO2 and is loaded into the RISC, where the passenger strand is discarded and the guide strand of miRNA guides this complex to bind the target mRNA with partial complementarity, leading to mRNA translation repression, degradation, or cleavage. Artificial siRNA or miRNA could be introduced directly to the cell via DDS to load into RISC for RNAi. Adapted from Ref. 27 with minor modifications. dsRNA = double-stranded RNA; RISC = RNA-induced silencing complex.

by the target cells usually via endocytosis, and protect it from enzymatic degradation within the cytoplasm. In this review we provide a comprehensive analysis of the different siRNA delivery strategies for enhancing bone regeneration.

\section{siRNA DDS for Bone Regeneration}

There are two major categories of DDSs that have been used for successfully delivering siRNA into osteoblastic cells, namely polymer-based and lipid-based systems. Polymers are long chains of repeating chemical units that can be modified to achieve a wide range of physicochemical properties. On the other hand, most lipid molecules used in DDS design are amphiphilic in nature, which means they contain hydrophilic and hydrophobic regions that allow them to form spherical vesicular structures in an aqueous environment. Both polymers and lipids are versatile and can be rationally designed to fabricate DDSs that provide targeted and controlled delivery of therapeutic agents. ${ }^{(74,75)}$ Viral DDSs have also been explored, mostly for in vitro studies and cell transfection; however, there are potential toxicity concerns associated with the use of live viruses, hindering their safe application in humans. The majority of studies included in this review utilized either polymer-based or lipid-based systems.

\section{Polymer-based DDS for siRNA delivery}

Synthetic and natural polymers have been used for the past 50 years to fabricate a multitude of microparticles and nanoparticles that can act as DDS for proteins, small molecules, and genetic material. ${ }^{(76,77)}$ Conjugating moieties such as antibodies, 
short peptide sequences, and aptamers have also been explored to improve DDS targeting to desired tissues once administered in vivo. Moreover, strategies used to overcome physiological barriers and improve intracellular uptake of polymer-siRNA systems have been thoroughly discussed in two excellent reviews. ${ }^{(76,78)}$

Poly(lactic-co-glycolic) acid (PLGA), a synthetic copolymer, has also been explored as a viable DDS for the delivery of siRNA. PLGA is biocompatible, biodegradable, and U.S. Food and Drug Administration (FDA)-approved for use in therapeutic devices. ${ }^{(79)}$ Hong and colleagues ${ }^{(80)}$ fabricated PLGA microparticles and were able to encapsulate siRNA and provide a controlled release in vitro for up to 40 days. siRNA against glucocorticoid receptors (GRs) was used in order to reduce endogenous glucocorticoid (GC) activity in human mesenchymal stem cell (MSCs). Elevated levels of GC were shown to reduce the ability of MSCs to proliferate by causing them to readily differentiate. Therefore, by silencing the expression of GRs and reducing the effect of GCs, MSCs were hypothesized to proliferate more readily and preferentially differentiate into an osteogenic lineage. The siRNA-mediated gene silencing resulted in significantly higher proliferation rates and differentiation toward osteoblasts, with lower adipogenic differentiation. The authors concluded that the PLGA microparticle system was a promising DDS for the transfection and delivery of siRNA to MSCs. Another study explored the use of PLGA microparticles encapsulating RANK siRNA in order to reduce bone resorption. ${ }^{(81)}$ RANK receptors on the surface of osteoclasts activate osteoclastic gene expression, which increases bone resorption. Therefore, silencing RANK was hypothesized to reduce bone resorption. The authors used the PLGA-siRNA microparticle system mixed with commercially available bone cement as a platform to seed murine cells on the surface. Although this study did not show any effect of this strategy on the function of osteoclasts and/or bone resorption, the authors demonstrated good bioactivity of the system and effective siRNA transfection of cells followed by inhibition of progression toward an osteoclastic phenotype (Fig. 3A).

In addition to the use of polymer-based particles, 3D polymeric hydrogels have also been explored in the context of DDSs for siRNA transfection of encapsulated cells. ${ }^{(82)}$ Nguyen and colleagues ${ }^{(71)}$ fabricated 3D polyethylene glycol (PEG) scaffolds for localized and sustained delivery of siRNA to differentiate encapsulated human MSCs within the hydrogel network. siRNA was first complexed with polyethyleneimine (PEI) - a highly cationic polymer-prior to incorporation in the hydrogel. The authors showed enhanced osteoblastic differentiation of the human MSCs using this hydrogel as a result of the prolonged delivery of Noggin siRNA or miRNA-20a (known to downregulate the expression of peroxisome proliferator-activated receptor gamma [PPAR- $\gamma$ ], a negative regulator of BMP2). This study demonstrated an interesting biomaterial methodology and approach; however, hMSCs from only one to two donors were examined (Fig. 3B).

Zhang and colleagues ${ }^{(83)}$ explored the use of a nanoparticle system fabricated from the synthetic copolymer, N-(2-hydroxypropyl) methacrylamide (HPMA) conjugated with poly-aspartic acid sequence and Alendronate (a bisphosphonate) for specific targeting to bone tissue. HPMA is a highly hydrophilic polymer that is non-immunogenic and improves blood circulation of therapeutic agents, and was therefore explored as a promising DDS for siRNA. ${ }^{(84)}$ Moreover, the octa-aspartic acid sequence (D-Asp8) and bisphosphonates have been shown to target bone tissue because they recognize and specifically bind to hydroxyapatite. ${ }^{(85)}$ Semaphorins are molecules involved in cellcell communication between osteoblasts and osteoclasts. Semaphorin 4d (Sema4d) specifically has been shown to be released by osteoclasts in order to repel osteoblasts and reduce mineralization. ${ }^{(86)}$ Therefore, gene silencing of Sema4d was explored as a treatment for osteoporosis in the mandibular alveolar bones of osteoporotic mouse models. The authors demonstrated that systemic administration of this bone-specific system led to targeting high bone turnover sites including the mandible alveolar region, peaking at 4 hours after the intravenous injection of the drug. They also showed that the treatment interferes with Sema4d in the target areas in vivo and decreases the bone loss resulting from osteoporosis by anabolic effects on bone regeneration without affecting osteoclast count (Fig. 3C). The latter finding is advantageous over the use of bisphosphonates, because bisphosphonates deteriorate osteoclasts and therefore can potentially affect natural bone turnover.

Atelocollagen is another 3D gel system that was developed for siRNA delivery. ${ }^{(87)}$ Atelocollagen is a decomposition product of type I collagen that is positively charged and thus can complex with siRNA. ${ }^{(87)}$ Kawakami and colleagues ${ }^{(88)}$ used Atelocollagen to complex the siRNA against Lnk (an inhibitory signaling molecule for stem cell renewal) in order to accelerate fracture healing. Primary mouse bone marrow cells and osteoblasts were transfected with siRNA against Lnk using lipofection. For the fracture model experiments, the siRNA was administered to the site of fracture in a 3D Atelocollagen gel, which underwent thermally induced gelation once injected in vivo $\left(37^{\circ} \mathrm{C}\right)$. This strategy was reported to contribute to a favorable environment for fracture repair by promoting both angiogenesis and osteogenesis and resulted in enhanced recovery from facture (Fig. $4 A$ ).

\section{Lipid-based DDS}

Lipid-based DDS have been more widely used for transfecting cells with siRNA than their polymeric counterparts. As a matter of fact, almost all commercially available transfection reagents are modified cationic liposome-based systems (eg, Lipofectamine from Invitrogen; DOTAP and DOSPER from Boehringer Mannheim Biochemicals; TransFast from Promega; Ambion from Thermo Fisher Scientific; and SUB9 kits from Precision NanoSystems). Liposomes are core-shell vesicular structures with at least one lipid bilayer. For siRNA transfection applications, the hydrophilic heads of amphiphilic lipids used to fabricate liposomes are usually cationic in nature. Neutral lipids such as cholesterol are used to stabilize the lipid bilayer structure. Cationic liposomes can easily complex with anionic siRNA through electrostatic attractions, and also adhere readily to the anionic membrane of cells. Moreover, liposomes have been commercially available for decades as DDSs for various therapeutic agents (eg, Ambisome), and therefore established methods are available for large-scale production of liposomes, which makes them attractive to pharmaceutical companies.

Commercially-available Ambion (polyamine-based transfection agent) was used to transfect MSCs with siRNAs against guanine nucleotide-binding protein alpha-stimulating activity polypeptide 1 (GNAS1) and prolyl hydroxylase domain containing protein 2 (PHD2) to target core binding factor alpha 1 (Cbfa1) and hypoxia-inducible factor 1 (HIF-1) pathways, respectively. ${ }^{\left({ }^{89}\right)}$ Activating GNAS1 leads to the proteolytic degradation of Cbfa1 (an osteogenic differentiation transcript factor); therefore, 


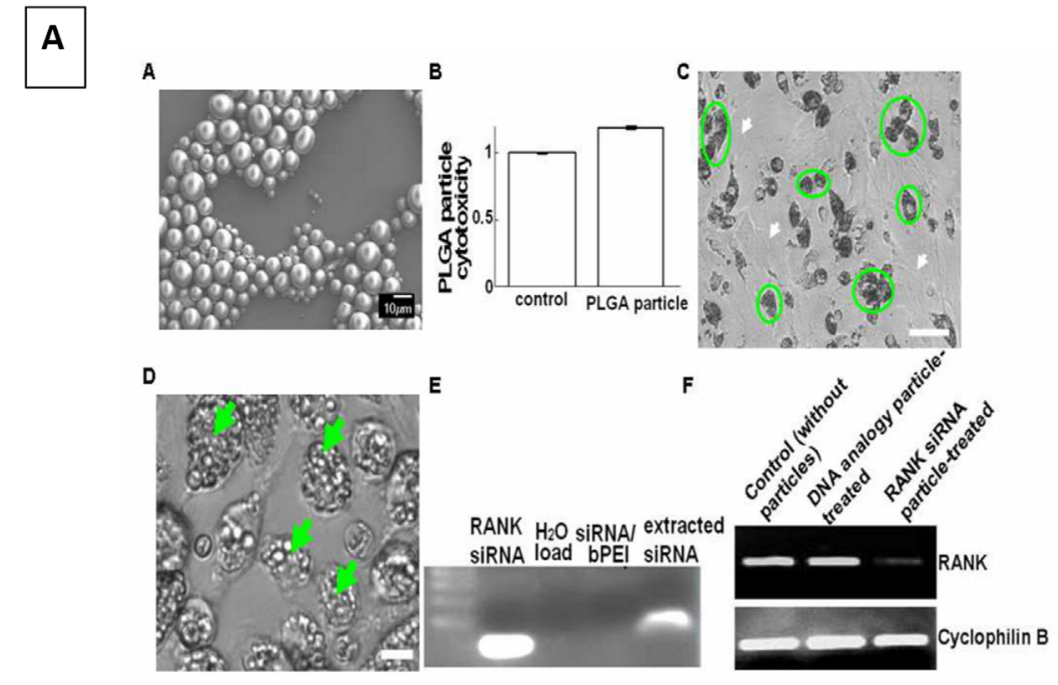

B
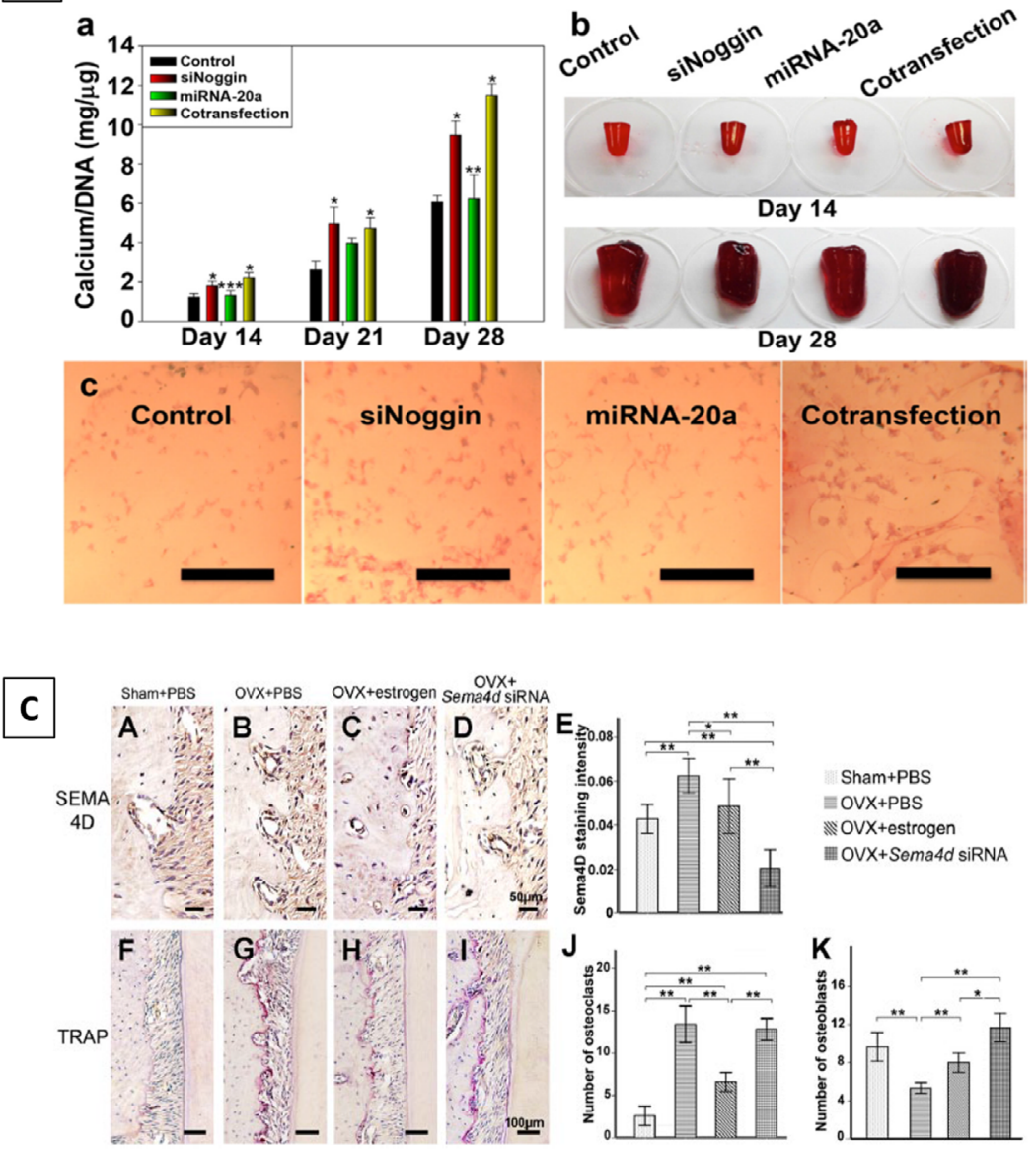

Fig. 3. (A) In vitro only: Encapsulation of siRNA in PLGA microparticles, physical, chemical, and functional properties of the microparticles. ${ }^{(81)}(B)$ In vitro only: Alizarin red staining of hydrogels. Calcium content measurement in the hydrogels containing Noggin-siRNA or miRNA showing increased calcium content compared to the control group, over time. ${ }^{(71)}(C)$ In vivo only: Representative immunohistological study of the intermolar regions in mice treated either with Sema4d siRNA or control: osteoblast and osteoclast numbers and Sema4d gene expression and knockdown. ${ }^{\left({ }^{(3)}\right.}$

silencing GNAS1 can lead to enhanced osteogenic differentiation. On the other hand, silencing PHD2 promotes the expression of angiogenic factors through the hypoxia pathway. Although in vitro analyses were not decisive regarding the effectiveness of the GNAS1 and PHD2 siRNAs in increasing osteogenesis, in vivo results demonstrated some promising results. In a sheep model of bone formation, siRNA-loaded chitosan-silk fibroin scaffolds were implanted over the 


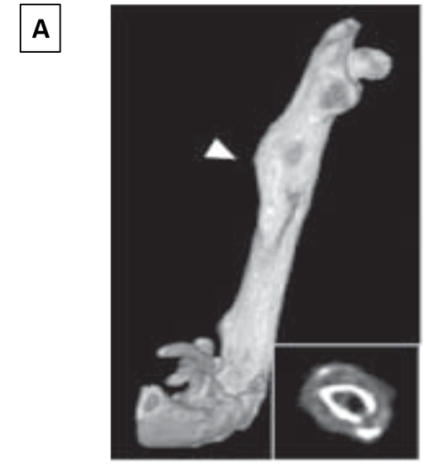

Lnk siRNA

C

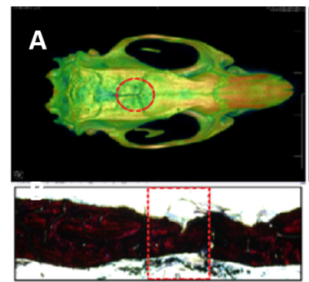

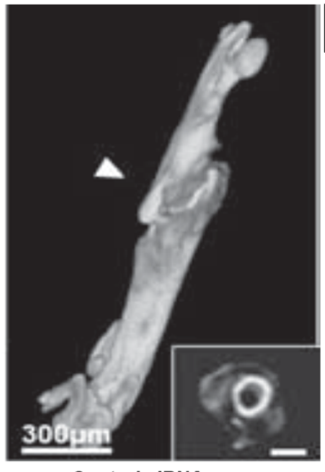

Control siRNA
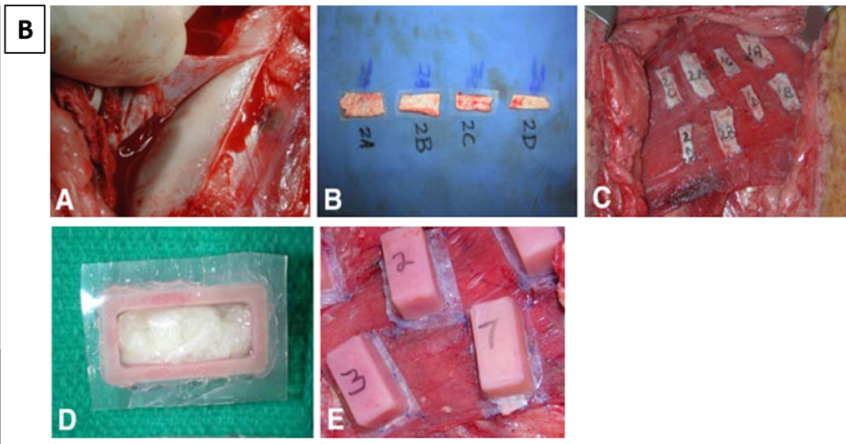

\section{c}
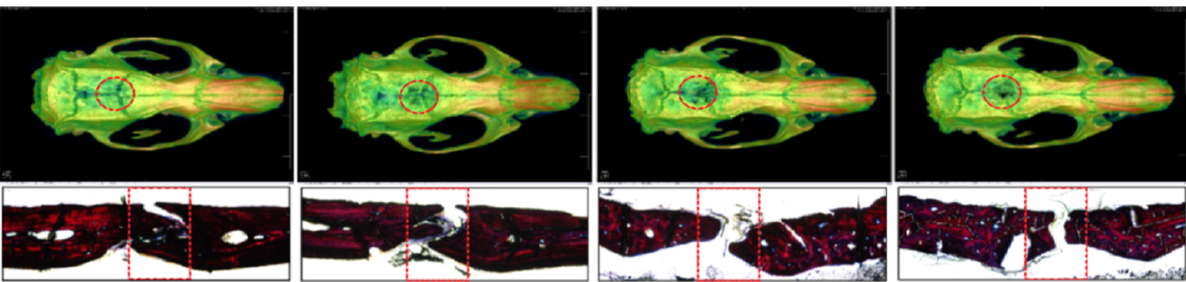

D

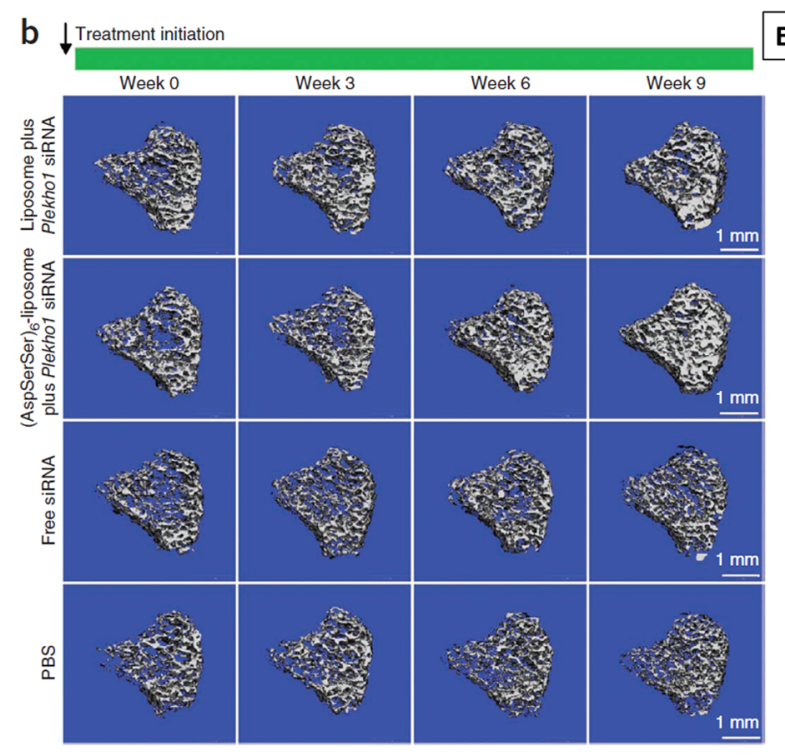

E b
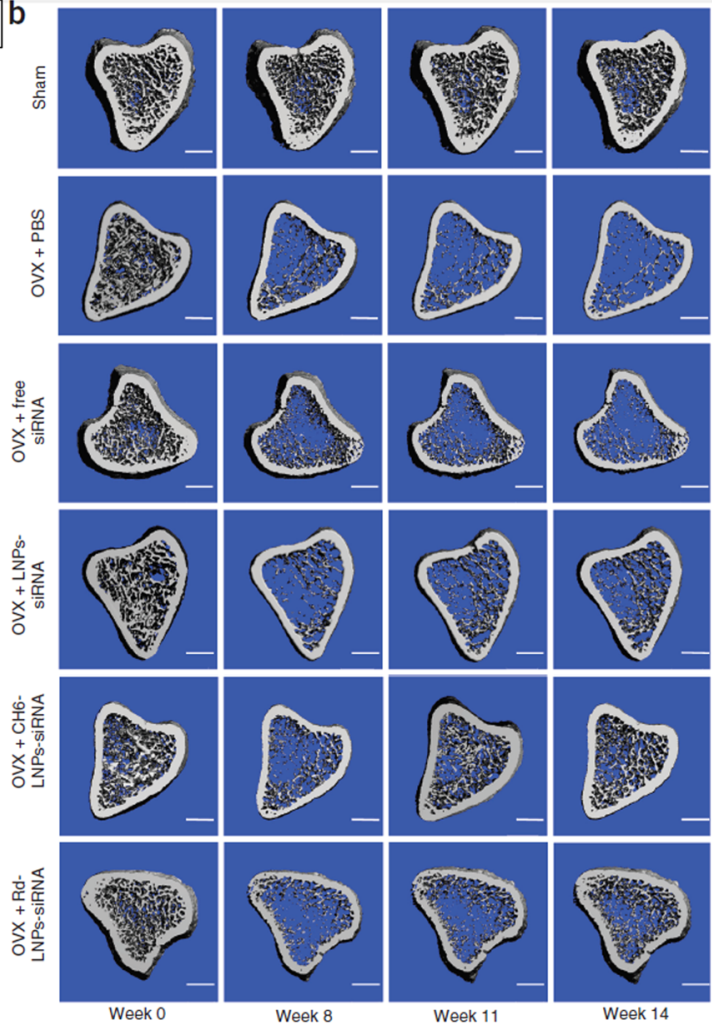

Fig. 4. (A) In vitro and in vivo, local delivery: $\mu$ CT reconstruction images of previously fractured rat femurs, treated with Lnk siRNA or control siRNA. ${ }^{(88)}$ $(B)$ In vitro and in vivo, local delivery: Representative immunohistological study of the intermolar regions in mice treated either with Sema4d siRNA or control: osteoblast and osteoclast numbers and Sema4d gene expression and knockdown. Serial pictures demonstrating different steps of surgical procedure in sheep. ${ }^{(89)}(C)$ In vitro and in vivo, local delivery: Bone repair in the rat calvarial defect model, $\mu C T$ imaging (top panel) and the corresponding histology imaging, Giessen's staining (bottom panel). ${ }^{(90)}(D)$ In vitro and in vivo, systemic delivery: Serial in vivo $\mu C T$ imaging of trabecular architecture of proximal tibias over the course of 9 weeks in animals treated with Plekho1 siRNA using different delivery methods, compared to control group. ${ }^{(94)}(E)$ In vitro and in vivo, systemic delivery: Serial in vivo three-dimensional trabecular architecture of the proximal tibia over 14 weeks in mouse models of osteoporosis treated with different siRNA delivery methods. ${ }^{(95)}$ 
periosteum. By day 70 there was an increase in bone volume in scaffolds containing GNAS1, PHD2, and the combination of both siRNAs (Fig. 4B).

Lipofectamine 2000 is a widely used, highly cationic, lipidbased DDS utilized for siRNA delivery. Jia and colleagues ${ }^{(90)}$ investigated the effects of two different siRNA-Lipofectamine 2000 complexes targeting casein kinase 2interaction protein 1 (Ckip-1) and soluble vascular endothelial growth factor (VEGF) receptor 1 (siFlt-1) to promote both osteogenesis and angiogenesis simultaneously in MSCs and also in vivo, using a skull critical size defect in rat models. These siRNA-Lipofectamine 2000 complexes were incorporated in a biodegradable lyophilized chitosan sponge as a scaffold for bone regeneration. The authors concluded that this scaffold system was able to maintain the siRNA efficiently over time and the synergistic effect of two different types of siRNA stimulated both osteogenesis and angiogenesis in vitro and enhanced bone regeneration in vivo (Fig. 4C). In a similar biological approach, $\mathrm{Xu}$ and colleagues $^{(91)}$ investigated the inhibitory effects of siRNA against PPAR- $\gamma$ on the suppression of adipogenic differentiation of cryopreserved human subcutaneous preadipocytes and also fresh fetal-femurderived MSCs. The authors used Lipofectamine 2000 for siRNA delivery to the cells and showed a significant suppression of adipocyte differentiation capacity in vitro. Lipofectamine 2000 complexed with siRNA was also used to knock down the expression of Chordin (BMP inhibitor) in human MSCs. ${ }^{(92)}$ Chordin knockdown resulted in increased expression of an osteoblastic cell marker (Alp) and extracellular mineral formation by these cells. Lipofectamine RNAiMAX is another liposomebased system that has been commercially developed for enhanced transfection of mesenchymal and neural stem cells. Chen and colleagues ${ }^{(93)}$ studied the effects of silencing BRE (Brain and Reproductive Organ-Expressed), a multifunctional adaptor protein important in cell survival, DNA repair, and stress response, on osteogenic and chondrogenic differentiation of human umbilical cord perivascular (HUCPV) multipotent progenitor cells. The authors found that the expression of BRE is decreased when chondrocytic or osteoblastic differentiation is induced in HUCPV mesenchymal cells. Therefore, Lipofectamine RNAiMAX was used to deliver siRNA against BRE to HUCPV progenitors. Both osteogenesis and chondrogenesis were accelerated posttransfection. Zhang and colleagues ${ }^{(94)}$ reported a systemically-administered and targeted approach to silence genes inhibitory to bone formation, utilizing siRNAs in osteogenic lineage cells. The group explored the use of DOTAP cationic liposomes targeting only bone-formation surfaces to deliver siRNA against Plekho1 in an in vivo osteoporotic rat model. The gene Plekho1 was recently discovered as a negative regulator of osteogenic lineage activity with little effect on bone resorption. The proposed cationic liposome in this study had a high binding affinity to poorly crystallized hydroxyapatite due to an (AspSerSer) 6 moiety. As such, this strategy was found effective in specifically targeting the bone-forming surfaces of the skeletal system and delivering the cargo to the osteogeniclineage cells (Fig. 4D). In a recent work, Liang and colleagues ${ }^{(95)}$ reported on a more efficient application of the same siRNA using a lipid nanoparticle whose surface was functionalized with an osteoblast-specific aptamer to deliver Plekho1 siRNA specifically to bone. Systemic application of this siRNA resulted in Plekho1 gene silencing followed by improved bone formation and bone microarchitecture and increased mechanical properties, tested in both healthy and osteoporotic animal models (Fig. 4E).
Lipidoids - another class of lipid-based nanoparticles-have a similar structure to liposomes and are synthesized by conjugating alkyl-acrylamides and amine molecules. They require fewer steps for fabrication compared to liposomes, which makes them preferential for high-throughout analysis of different therapeutic agents. ${ }^{(96)}$ Moreover, it has been shown that at a low serum level (2\%), the transfection of human umbilical vein endothelial cells (HUVECs) using lipidoid was comparable to Lipofectamine 2000. However, at a normal serum level (10\%), lipidoids had superior transfection efficiency compared to Lipofectamine 2000. This is another advantage of using lipidoids over cationic liposomes, which easily aggregate in the presence of high serum concentrations. Ramasubramanian and colleagues ${ }^{(97)}$ examined the effects of delivering BMP2 DNA in conjunction with siRNA against both Noggin and GNAS to a human fetal osteoblast (immortalized) cell line using a lipidoid called NA114, which was previously demonstrated to be an efficient nanoparticle for siRNA delivery. ${ }^{(98)}$ Cell transfection with BMP2 DNA or Noggin and GNAS siRNA resulted in increased cell apoptosis as well as decreased proliferation and viability compared to sham DNA or siRNA treated cells. The authors concluded that the response of progenitor cells and immortalized cell populations to exogenous osteogenic gene delivery is different, and highlighted the need for a targeted gene delivery mechanism for bone regeneration.

\section{Other DDS}

El-Fiqi and colleagues ${ }^{(99)}$ fabricated and utilized bioactive glass nanoparticles (BGn) smaller than $100 \mathrm{~nm}$ with $3-\mathrm{nm}$ to $5-\mathrm{nm}$ mesopores for delivery of both small chemical drugs (Na-ampicillin) and small nucleic acids (siRNA). They showed a sustained release profile of siRNA from such nanoparticles up to 3 days and a high cell transfection efficiency (roughly $80 \%$ ) followed by about $85 \%$ target gene silencing in HeLa cells. The authors examined the cytotoxicity of their delivery system on mouse preosteoblastic cell line and rat bone marrow stromal cells.

A summary of preclinical studies employing siRNA approaches directly for bone regeneration is provided in Table 1.

\section{Discussion}

\section{Universal challenges facing siRNA therapeutics}

siRNA-based therapies have been gaining much attention, and their use in a wide range of applications, including bone regeneration, has been promising. However, there are some universal challenges facing the use of siRNA therapeutics. Almost a decade ago, three main off-target effects of siRNA were discovered with potential unwanted side effects. ${ }^{(100)}$ The first was the silencing of a number of unintended genes through partial sequence complementarity; second was an inflammatory response caused by either the siRNA or DDS used; and the third surprising event was the saturation of endogenous RNAi machinery, which could affect normal miRNA functionality. ${ }^{(100)}$ In order to avoid silencing unintended genes, there has been evidence that lowering the concentration of siRNA used can significantly reduce these unwanted effects. ${ }^{(101)}$ Lowering the concentration to the minimum effective limit can also reduce the burden on RNAi machinery and avoid disrupting physiological processes. Different factors that trigger an immune reaction in response to siRNA sequence and length, as well as the siRNA-DDS complexes, have been thoroughly explored in an excellent review. ${ }^{(100)}$ For example, it was shown that the motif $5^{\prime}-U_{G U G U}-3^{\prime}$ is immune-stimulatory, 


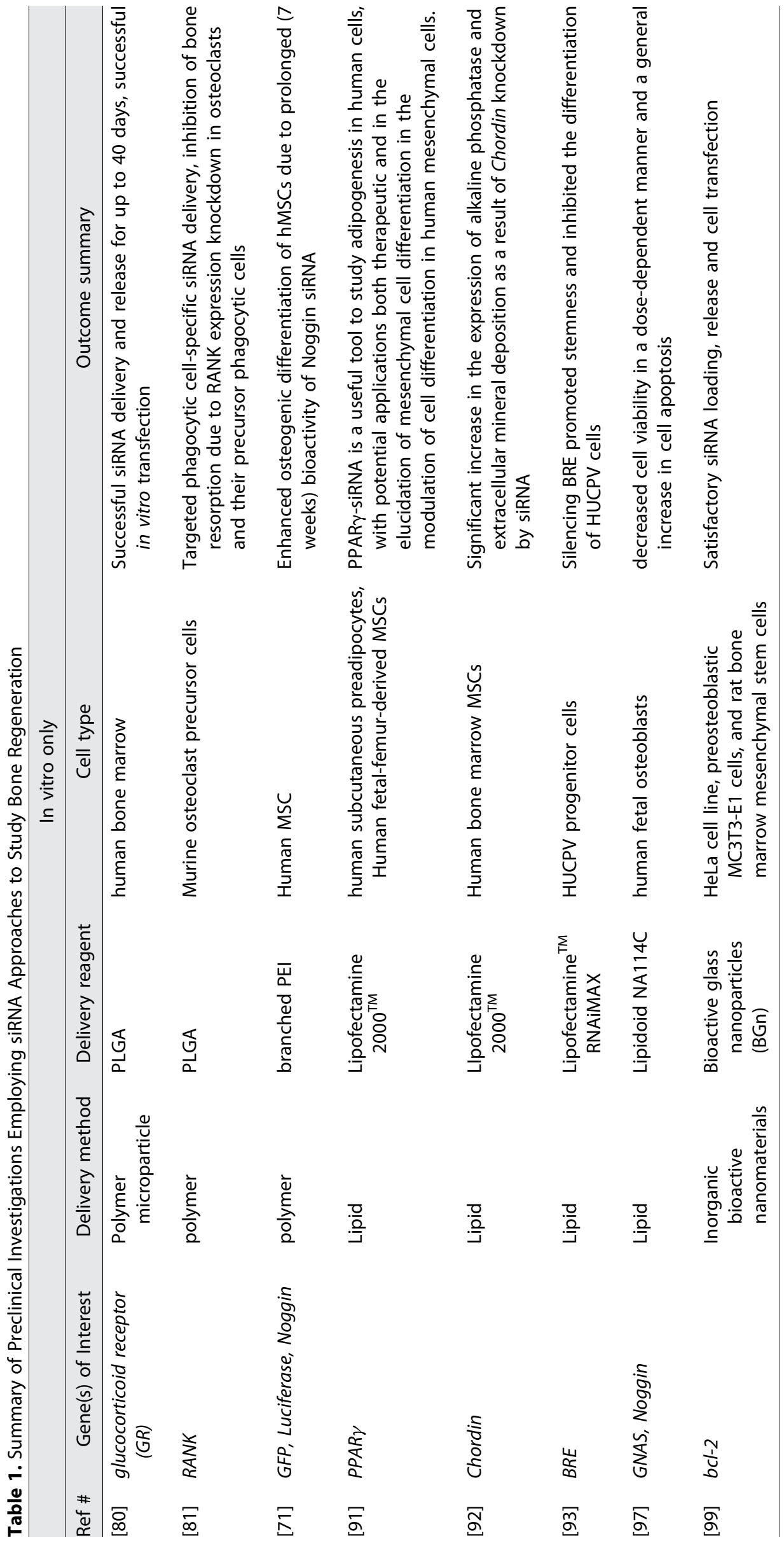




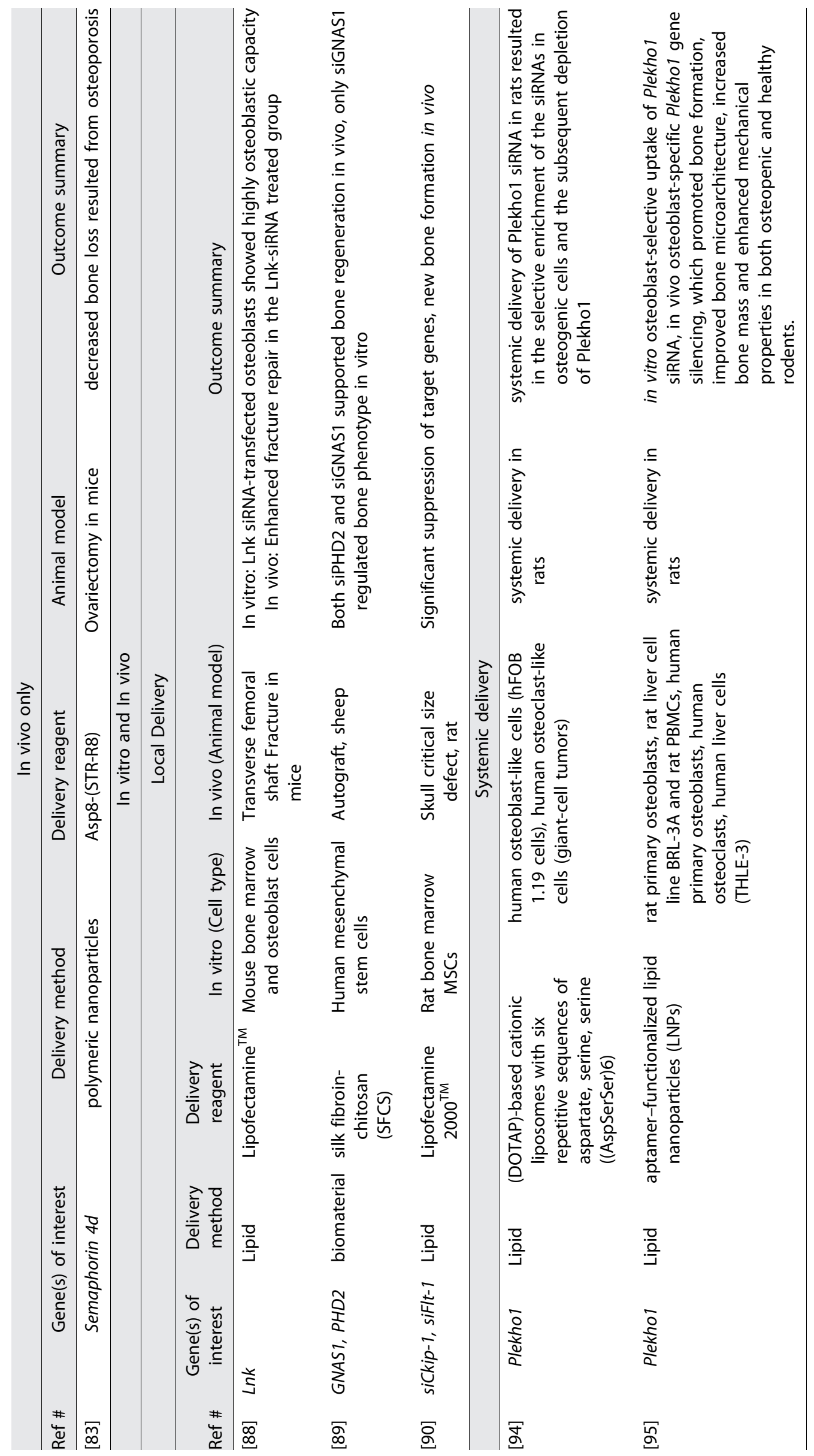


and therefore, should be avoided when designing siRNA sequences for bone regeneration. ${ }^{(102)}$

\section{Strategies to improve efficacy of siRNA therapies in bone regeneration}

Besides the universal barriers that any siRNA DDS should overcome, ${ }^{(78)}$ there are a few additional design criteria that can improve the efficacy of siRNA therapeutics in bone regeneration applications.

\section{Incorporation of siRNA particles in injectable matrices}

Incorporating siRNA-loaded particles inside injectable biodegradable matrices can be very beneficial in localizing the delivery of siRNA at the site of a bone defect or fracture, maximizing its therapeutic effect. Such an approach would also circumvent various physiological barriers the DDS-siRNA would have to overcome in the case of systemic administration. Moreover, the injectable system does not have to be a passive carrier of the siRNA-loaded particles, instead, it could be modified to provide a cumulative bone regeneration effect. For example, incorporating inorganic osteoconductive components such as bioactive glass, hydroxyapatite, or tricalcium phosphates into the injectable matrix can accelerate bone formation and improve bone quality. ${ }^{(103,104)}$ The choice of an osteoconductive polymer, such as collagen or chitosan, to fabricate the injectable matrix can further improve bone formation. ${ }^{(104-106)}$ Finally, controlling the rate of degradation can provide a continuous release of the siRNA-loaded particles and therefore prolong the therapeutic effect. Such control can be achieved by varying the degree of polymer crosslinking or by utilizing different crosslinking methods (ie, chemical or physical crosslinking).

\section{Functionalizing targeting moieties on siRNA-DDS complexes}

The addition of targeting moieties is another important approach to improve the efficacy of siRNA delivery. The three most commonly used moieties for bone regeneration are bisphosphonates, bone-specific oligopeptides, and aptamers. Poly-aspartic acid sequences (eg, $(\mathrm{Asp})_{8}$ ) are oligopeptides discovered to have a high affinity for crystalline hydroxyapatite present on bone-resorption surfaces, and have therefore been used as targeting moieties to bone tissue. ${ }^{(107,108)}$ Interestingly, the oligopeptide (AspSerSer) 6 was shown to have a higher affinity for more amorphous hydroxyapatite resembling mineralizing nodules as compared to highly crystalline hydroxyapatite, and has therefore been utilized to target bone-forming surfaces. ${ }^{(94,108)}$ Bisphosphonates, on the other hand, have high affinity to the calcium present in hydroxyapatite and can therefore target both bone-resorption and bone-formation surfaces. ${ }^{(109)}$ On the other hand, a recent study done by Liang and colleagues ${ }^{(95)}$ demonstrates the use of aptamer-functionalized nanoparticles to selectively deliver siRNA to osteoblasts, which makes it a "cell-specific" DDS. Finding such moieties that increase cellular specificity to osteoblasts will improve the therapeutic effect and clinical relevance of DDS-siRNA systems.

\section{Incorporation of osteogenic and angiogenic factors}

Incorporating low concentrations of osteogenic factors (eg, BMPs, bFGF, etc.) along with siRNA can further improve bone regeneration. However, similar to siRNA, using very low and safe concentrations of osteogenic factors (eg, rhBMP2 and rhBMP7) is critical in order to avoid unwanted side effects such as ectopic bone formation and toxicity. Similarly, incorporating angiogenic factors such as VEGF can accelerate bone formation by increasing the blood supply to the fracture site. ${ }^{(110)}$ The synergistic effect of siRNA therapy and osteogenic/angiogenic factors is therefore believed to be superior to the use of siRNA alone.

\section{Additional criteria to ensure clinical safety}

In addition to improving the therapeutic effect of any siRNA therapies mentioned above, there are also safety issues to be taken into account in order to move the technology into a clinical setting. The first is to fabricate the DDS and injectable matrices using degradable, biocompatible biomaterials, with degradation byproducts that are noncytotoxic, and that can be cleared readily from the body, without accumulation in the liver or other organs. Cationic polymers have been widely used for oligonucleotide delivery because of their ability to readily complex with DNA and RNA. ${ }^{(11)}$ However, upon degradation some cationic polymers can induce cytotoxic effects to surrounding cells and cause red blood cell lysis. ${ }^{(12)}$ For example, it has been shown that poly(L-lysine) (PLL) and PEl are more cytotoxic at concentrations higher than $0.1 \mathrm{mg} / \mathrm{mL}$ as compared to other cationic polymers such as poly (diallyldimethylammonium chloride) or diethylaminoethyl-dextran. ${ }^{(112)}$ The cytotoxicity of PEI has also been attributed to its limited biodegradability in vivo. Therefore, hydrolysable polymers that can degrade more readily have been getting more attention in the literature. ${ }^{(113)}$ One group of polymers that have been shown to be both biocompatible in humans and highly effective in siRNA incorporation and delivery are cyclodextrin-containing polymers. ${ }^{(14)}$

Cationic lipids can induce a cytotoxic effect and reduce cell viability. For example, a study done in vitro found that at a concentration of $40 \mu \mathrm{M}$, cationic liposomes fabricated using dimethyldioctadecyl-ammonium bromide (DDAB) and dioleoylphosphatidylethanolamine (DOPE), were more cytotoxic compared to those fabricated using $\mathrm{N}[\mathrm{I}$-(2,3-dioleoyloxy) propyl]-N, $\mathrm{N}, \mathrm{N}$-trimethylammonium-methylsulfate (DOTAP). ${ }^{(15)}$ Cationic lipids can also accumulate in Kupffer cells in the liver and induce an inflammatory response that can ultimately cause liver damage. ${ }^{(116)}$ Surface charge of the nanoparticles is not the only factor that determines cytotoxicity, but also the shape, size, hydrophilicity, concentration, and length of exposure. ${ }^{(113)}$ All of these factors also dictate whether the siRNA-DDS complexes can end up accumulating in organs such as liver and kidney. Readers are encouraged to refer to these reviews for further discussion on this specific topic. ${ }^{(116,117)}$

\section{Conclusion and Future Outlook}

siRNA therapies have emerged as excellent genetic tools in biology and are also becoming the next frontier in gene therapy, holding great therapeutic promise. Please visit the Google-based World of RNAi Therapeutics, ${ }^{(118)}$ which pinpoints all the companies currently involved with RNAi globally and the list of their RNAi agents in clinical trials or under investigation. Advanced nanotechnology offers novel solutions for improved and efficient DDSs. Nevertheless, our search revealed no current or previous clinical trials utilizing siRNA therapy for musculoskeletal defects or disorders. Investigators have identified a large number of regulatory signals and targets playing central roles in bone development and repair that offer a long list of potential attractive candidates for 
translational research and siRNA therapeutics. Despite several barriers in the systemic application of such therapeutics, local application of siRNA at the site of bone defects is advantageous and is less complex. This is mainly because if delivered at the site of target tissue, significantly lower doses of siRNA are required to achieve the therapeutic effect locally; ${ }^{(119,120)}$ this in turn reduces the associated risks and costs of such treatment for patients. By focusing local delivery of siRNA at the site of bone defects, undesired systemic effects and obstacles in systemic delivery could also be avoided. Though RNAi therapeutics is still a nascent field, advances in siRNA design, biochemical modifications, and nanosized DDS are contributing to a faster translation of preclinical experiments to clinical trials. High rates of skeletal injuries with consequent social, emotional, and economic impacts on individuals warrants significant investment in drug discovery and development in this area and provides a significant unmet global market for pharmaceutical industries.

\section{Disclosures}

All authors state that they have no conflicts of interest.

\section{Acknowledgments}

We gratefully acknowledge Nicholas Distasio and Timothy Johns for proofreading the manuscript.

Authors' roles: SG developed the general concept of the manuscript and performed the literature search. SG and MM reviewed the articles. SG, MM and AA drafted the manuscript. $\mathrm{RH}$ and MT critically reviewed the manuscript and all authors approved the final version.

\section{References}

1. Luo J, Sun $M H$, Kang Q, et al. Gene therapy for bone regeneration. Curr Gene Ther. 2005;5(2):167-79.

2. Marsell R, Einhorn TA. The biology of fracture healing. Injury. 2011;42(6):551-5.

3. Giannoudis PV, Einhorn TA, Marsh D. Fracture healing: the diamond concept. Injury. 2007;38 Suppl 4:S3-6.

4. Einhorn TA, Gerstenfeld LC. Fracture healing: mechanisms and interventions. Nat Rev Rheumatol. 2015;11(1):45-54.

5. Im Gl. Nonviral gene transfer strategies to promote bone regeneration. J Biomed Mater Res A. 2013;101(10):3009-18.

6. Balmayor ER. Targeted delivery as key for the success of small osteoinductive molecules. Adv Drug Deliv Rev. 2015 Nov 1;94:13-27.

7. Polyzois VD, Stathopoulos IP, Lampropoulou-Adamidou K, Vasiliadis ES, Vlamis J, Pneumaticos SG. Strategies for managing bone defects of the lower extremity. Clin Podiatr Med Surg. 2014;31(4):577-84.

8. Sen MK, Miclau T. Autologous iliac crest bone graft: should it still be the gold standard for treating nonunions? Injury. 2007;38 Suppl 1: S75-80.

9. Myeroff $C$, Archdeacon M. Autogenous bone graft: donor sites and techniques. J Bone Joint Surg Am. 2011;93(23):2227-36.

10. Tare RS, Kanczler J, Aarvold A, Jones AM, Dunlop DG, Oreffo RO. Skeletal stem cells and bone regeneration: translational strategies from bench to clinic. Proc Inst Mech Eng H. 2010;224(12):1455-70.

11. Santos JL, Pandita D, Rodrigues J, Pêgo AP, Granja PL, Tomás H. Non-viral gene delivery to mesenchymal stem cells: methods, strategies and application in bone tissue engineering and regeneration. Curr Gene Ther. 2011;11(1):46-57.

12. Simpson AH, Mills L, Noble B. The role of growth factors and related agents in accelerating fracture healing. J Bone Joint Surg $\mathrm{Br}$. 2006;88(6):701-5
13. Aagaard L, Rossi JJ, RNAi therapeutics: principles, prospects and challenges. Adv Drug Deliv Rev. 2007;59(2-3):75-86.

14. Gautschi OP, Frey SP, Zellweger R. Bone morphogenetic proteins in clinical applications. ANZ J Surg. 2007;77(8):626-31.

15. Haidar ZS, Hamdy RC, Tabrizian M. Delivery of recombinant bone morphogenetic proteins for bone regeneration and repair. Part $A$ Current challenges in BMP delivery. Biotechnol Lett. 2009;31(12): 1817-24.

16. Haidar ZS, Hamdy RC, Tabrizian M. Delivery of recombinant bone morphogenetic proteins for bone regeneration and repair. Part B: Delivery systems for BMPs in orthopaedic and craniofacial tissue engineering. Biotechnol Lett. 2009;31(12):1825-35.

17. Croteau S, Rauch F, Silvestri A, Hamdy RC. Bone morphogenetic proteins in orthopedics: from basic science to clinical practice. Orthopedics. 1999;22(7):686-95; quiz 696-7.

18. Evans $\mathrm{CH}$. Gene therapy for bone healing. Expert Rev Mol Med. 2010;12:e18.

19. Epstein NE. Complications due to the use of BMP/INFUSE in spine surgery: the evidence continues to mount. Surg Neurol Int. 2013;4(Suppl 5):S343-52.

20. Choi YJ, Lee JY, Park JH, et al. The identification of a heparin binding domain peptide from bone morphogenetic protein- 4 and its role on osteogenesis. Biomaterials. 2010;31(28):7226-38.

21. Lo KW, Ashe KM, Kan HM, Laurencin CT. The role of small molecules in musculoskeletal regeneration. Regen Med. 2012;7(4):535-49.

22. Lo KW, Ulery BD, Kan HM, Ashe KM, Laurencin CT. Evaluating the feasibility of utilizing the small molecule phenamil as a novel biofactor for bone regenerative engineering. J Tissue Eng Regen Med. 2014;8(9):728-36.

23. Lo KW, Kan HM, Laurencin CT. Short-term administration of small molecule phenamil induced a protracted osteogenic effect on osteoblast-like MC3T3-E1 cells. J Tissue Eng Regen Med. Forthcoming. Epub 2013 Jul 30. DOI:10.1002/term.1786.

24. Evans CH. Gene delivery to bone. Adv Drug Deliv Rev. 2012;64(12): 1331-40.

25. Balmayor ER, van Griensven M. Gene therapy for bone engineering. Front Bioeng Biotechnol. 2015;3:9.

26. Evans $\mathrm{CH}$, Huard J. Gene therapy approaches to regenerating the musculoskeletal system. Nat Rev Rheumatol. 2015;11(4): 234-42.

27. Ozcan G, Ozpolat B, Coleman RL, Sood AK, Lopez-Berestein G. Preclinical and clinical development of siRNA-based therapeutics. Adv Drug Deliv Rev. 2015;87:108-19.

28. Lam JK, Chow MY, Zhang Y, Leung SW. siRNA versus miRNA as therapeutics for gene silencing. Mol Ther Nucleic Acids. 2015;4: e252.

29. Dykxhoorn DM, Novina CD, Sharp PA. Killing the messenger: short RNAs that silence gene expression. Nat Rev Mol Cell Biol. 2003;4(6):457-67.

30. Agrawal N, Dasaradhi PV, Mohmmed A, Malhotra P, Bhatnagar RK, Mukherjee SK. RNA interference: biology, mechanism, and applications. Microbiol Mol Biol Rev. 2003;67(4):657-85.

31. Bender J. A vicious cycle: RNA silencing and DNA methylation in plants. Cell. 2001;106(2):129-32.

32. Bernstein E, Caudy AA, Hammond SM, Hannon GJ. Role for a bidentate ribonuclease in the initiation step of RNA interference. Nature. 2001;409(6818):363-6.

33. Fagard $M$, Vaucheret $H$. (Trans)gene silencing in plants: how many mechanisms? Annu Rev Plant Physiol Plant Mol Biol. 2000 51:167-94.

34. Elbashir SM, Martinez J, Patkaniowska A, Lendeckel W, Tuschl T. Functional anatomy of siRNAs for mediating efficient RNAi in Drosophila melanogaster embryo lysate. EMBO J. 2001;20(23): 6877-88.

35. tenOever BR. RNA viruses and the host microRNA machinery. Nat Rev Microbiol. 2013;11(3):169-80.

36. Arroyo JD, Gallichotte EN, Tewari M. Systematic design and functional analysis of artificial microRNAs. Nucleic Acids Res. 2014;42(9):6064-77. 
37. Hammond SM, Caudy AA, Hannon GJ. Post-transcriptional gene silencing by double-stranded RNA. Nat Rev Genet. 2001;2(2): 110-9.

38. Sharp PA. RNA interference-2001. Genes Dev. 2001;15(5):485-90.

39. Bernstein E, Denli AM, Hannon GJ. The rest is silence. RNA. 2001;7(11):1509-21.

40. Wittrup A, Lieberman J. Knocking down disease: a progress report on siRNA therapeutics. Nat Rev Genet. 2015;16(9):543-52.

41. Paddison PJ, Caudy AA, Bernstein E, Hannon GJ, Conklin DS. Short hairpin RNAs (shRNAs) induce sequence-specific silencing in mammalian cells. Genes Dev. 2002;16(8):948-58.

42. Moore CB, Guthrie EH, Huang MT, Taxman DJ. Short hairpin RNA (shRNA): design, delivery, and assessment of gene knockdown. Methods Mol Biol. 2010;629:141-58.

43. Davidson BL, McCray PB Jr. Current prospects for RNA interferencebased therapies. Nat Rev Genet. 2011;12(5):329-40.

44. Borel F, Kay Ma, Mueller C. Recombinant AAV as a platform for translating the therapeutic potential of RNA interference. Mol Ther. 2014;22(4):692-701.

45. Fire A, Xu S, Montgomery MK, Kostas SA, Driver SE, Mello CC. Potent and specific genetic interference by double-stranded RNA in Caenorhabditis elegans. Nature. 1998;391(6669):806-11.

46. McBride JL, Boudreau RL, Harper SQ, et al. Artificial miRNAs mitigate shRNA-mediated toxicity in the brain: implications for the therapeutic development of RNAi. Proc Natl Acad Sci U S A. 2008;105(15):5868-73.

47. Chang N, Xiu L, Li L. Sphingosine 1-phosphate receptors negatively regulate collagen type I/III expression in human bone marrowderived mesenchymal stem cell. J Cell Biochem. 2014;115(2): 359-67.

48. Cho YA, Jue SS, Bae WJ, et al. PIN1 inhibition suppresses osteoclast differentiation and inflammatory responses. J Dent Res. 2015;94(2): 371-80.

49. de Gorter DJ, van Dinther M, Korchynskyi O, ten Dijke P. Biphasic effects of transforming growth factor beta on bone morphogenetic protein-induced osteoblast differentiation. J Bone Miner Res. 2011;26(6):1178-87.

50. Deng $M$, Liu $P$, Xiao $H$, et al. Improving the osteogenic efficacy of BMP2 with mechano growth factor by regulating the signaling events in BMP pathway. Cell Tissue Res. 2015 Sep;361(3): 723-31.

51. Du Z, Wang L, Zhao Y, et al. Sympathetic denervation-induced MSC mobilization in distraction osteogenesis associates with inhibition of MSC migration and osteogenesis by norepinephrine/adrb3. PLoS One. 2014;9(8):e105976.

52. Guérit $D$, Brondello JM, Chuchana $P$, et al. FOXO3A regulation by miRNA-29a controls chondrogenic differentiation of mesenchymal stem cells and cartilage formation. Stem Cells Dev. 2014;23(11): 1195-205.

53. Khaddam M, Huet E, Vallée B, et al. EMMPRIN/CD147 deficiency disturbs ameloblast-odontoblast cross-talk and delays enamel mineralization. Bone. 2014;66:256-66.

54. Kong X, Liu Y, Ye R, et al. GSK3beta is a checkpoint for TNF-alphamediated impaired osteogenic differentiation of mesenchymal stem cells in inflammatory microenvironments. Biochim Biophys Acta. 2013;1830(11):5119-29.

55. Kook SH, Jeon YM, Lim SS, et al. Fibroblast growth factor-4 enhances proliferation of mouse embryonic stem cells via activation of c-Jun signaling. PLoS One. 2013;8(8):e71641.

56. Kook SH, Lim SS, Cho ES, et al. COMP-angiopoietin 1 increases proliferation, differentiation, and migration of stem-like cells through Tie-2-mediated activation of p38 MAPK and PI3K/Akt signal transduction pathways. Biochem Biophys Res Commun. 2014;455(3-4):371-7.

57. Lee SI, Kim GT, Kim HJ, Park SH, Kim EC. NOD2 mediates odontoblast differentiation and RANKL expression. J Dent Res. 2014;93(7):678-84

58. Levi B, Hyun JS, Nelson ER, et al. Nonintegrating knockdown and customized scaffold design enhances human adipose-derived stem cells in skeletal repair. Stem Cells. 2011;29(12):2018-29.
59. Oh Yl, Kim JH, Kang CW. Protective effect of short-term treatment with parathyroid hormone 1-34 on oxidative stress is involved in insulin-like growth factor-I and nuclear factor erythroid 2-related factor 2 in rat bone marrow derived mesenchymal stem cells. Regul Pept. 2014;189:1-10.

60. Ozeki N, Kawai R, Yamaguchi $H$, et al. IL-1beta-induced matrix metalloproteinase-13 is activated by a disintegrin and metalloprotease-28-regulated proliferation of human osteoblast-like cells. Exp Cell Res. 2014;323(1):165-77.

61. Shih YR, Hwang Y, Phadke A, et al. Calcium phosphate-bearing matrices induce osteogenic differentiation of stem cells through adenosine signaling. Proc Natl Acad Sci U S A. 2014;111(3):990-5.

62. Singhatanadgit W, Salih V, Olsen I. RNA interference of the BMPR-IB gene blocks BMP-2-induced osteogenic gene expression in human bone cells. Cell Biol Int. 2008;32(11):1362-70.

63. Someya H, Fujiwara H, Nagata K, et al. Thymosin beta 4 is associated with RUNX2 expression through the Smad and Akt signaling pathways in mouse dental epithelial cells. Int J Mol Med. 2015;35(5):1169-78.

64. Son GY, Yang YM, Park WS, Chang I, Shin DM. Hypotonic stress induces RANKL via transient receptor potential melastatin 3 (TRPM3) and vaniloid 4 (TRPV4) in human PDL cells. J Dent Res 2015;94(3):473-81.

65. Song $K$, Krause $C$, Shi $S$, et al. Identification of a key residue mediating bone morphogenetic protein (BMP)- 6 resistance to noggin inhibition allows for engineered BMPs with superior agonist activity. J Biol Chem. 2010;285(16):12169-80.

66. Tiaden AN, Breiden M, Mirsaidi A, et al. Human serine protease HTRA1 positively regulates osteogenesis of human bone marrowderived mesenchymal stem cells and mineralization of differentiating bone-forming cells through the modulation of extracellular matrix protein. Stem Cells. 2012;30(10):2271-82.

67. $\mathrm{Xu}$ J, Yu B, Hong C, Wang CY. KDM6B epigenetically regulates odontogenic differentiation of dental mesenchymal stem cells. Int J Oral Sci. 2013;5(4):200-5.

68. Yan J, Zhang C, Zhao Y, et al. Non-viral oligonucleotide antimiR-138 delivery to mesenchymal stem cell sheets and the effect on osteogenesis. Biomaterials. 2014;35(27):7734-49.

69. Yeh Y, Yang Y, Yuan K. Importance of CD44 in the proliferation and mineralization of periodontal ligament cells. J Periodontal Res. 2014;49(6):827-35.

70. Zhang W, Liu N, Shi H, et al. Upregulation of BMSCs osteogenesis by positively-charged tertiary amines on polymeric implants via charge/iNOS signaling pathway. Sci Rep. 2015;5:9369.

71. Nguyen MK, Jeon O, Krebs MD, Schapira D, Alsberg E. Sustained localized presentation of RNA interfering molecules from in situ forming hydrogels to guide stem cell osteogenic differentiation. Biomaterials. 2014;35(24):6278-86.

72. Kanasty R, Dorkin JR, Vegas A, Anderson D. Delivery materials for siRNA therapeutics. Nat Mater. 2013;12(11):967-77.

73. Gavrilov K, Saltzman WM. Therapeutic siRNA: principles, challenges, and strategies. Yale J Biol Med. 2012;85(2):187-200.

74. Krebs MD, Jeon $\mathrm{O}$, Alsberg E. Localized and sustained delivery of silencing RNA from macroscopic biopolymer hydrogels. J Am Chem Soc. 2009;131(26):9204-6.

75. Krebs MD, Alsberg E. Localized, targeted, and sustained siRNA delivery. Chemistry. 2011;17(11):3054-62.

76. Liechty WB, Kryscio DR, Slaughter BV, Peppas NA. Polymers for drug delivery systems. Annu Rev Chem Biomol Eng. 2010;1:149-73.

77. Huynh CT, Nguyen MK, Tonga GY, Longé L, Rotello VM, Alsberg E. Photocleavable hydrogels for light-triggered siRNA release. Adv Healthc Mater. 2016 Feb;5(3):305-10.

78. Whitehead KA, Langer R, Anderson DG. Knocking down barriers: advances in siRNA delivery. Nat Rev Drug Discov. 2009;8(2):129-38.

79. Makadia HK, Siegel SJ. Poly lactic-co-glycolic acid (PLGA) as biodegradable controlled drug delivery carrier. Polymers. 2011;3(3):1377-97.

80. Hong L, Wei N, Joshi V, et al. Effects of glucocorticoid receptor small interfering RNA delivered using poly lactic-co-glycolic acid microparticles on proliferation and differentiation capabilities of human 
mesenchymal stromal cells. Tissue Eng Part A. 2012;18(78):775-84.

81. Wang Y, Tran KK, Shen H, Grainger DW. Selective local delivery of RANK siRNA to bone phagocytes using bone augmentation biomaterials. Biomaterials. 2012;33(33):8540-7.

82. Nguyen K, Dang PN, Alsberg E. Functionalized, biodegradable hydrogels for control over sustained and localized siRNA delivery to incorporated and surrounding cells. Acta Biomater. 2013;9(1): 4487-95.

83. Zhang Y, Wei L, Miron RJ, Zhang Q, Bian Z. Prevention of alveolar bone loss in an osteoporotic animal model via interference of semaphorin 4d. J Dent Res. 2014;93(11):1095-100.

84. Ulbrich K, Subr V, Structural and chemical aspects of HPMA copolymers as drug carriers. Adv Drug Deliv Rev. 2010;62(2): 150-66.

85. Wang D, Sima M, Mosley RL, et al. Pharmacokinetic and biodistribution studies of a bone-targeting drug delivery system based on $\mathrm{N}$-(2-hydroxypropyl) methacrylamide copolymers. Mol Pharm. 2006;3(6):717-25.

86. Zhang Y, Wei L, Miron RJ, Shi B, Bian Z. Anabolic bone formation via a site-specific bone-targeting delivery system by interfering with semaphorin 4D expression. J Bone Miner Res. 2015;30(2):286-96.

87. Minakuchi Y, Takeshita F, Kosaka N, et al. Atelocollagen-mediated synthetic small interfering RNA delivery for effective gene silencing in vitro and in vivo. Nucleic Acids Res. 2004;32(13):e109.

88. Kawakami $Y$, li $M$, Matsumoto $T$, et al. A small interfering RNA targeting Lnk accelerates bone fracture healing with early neovascularization. Lab Invest. 2013;93(9):1036-53.

89. Rios CN, Skoracki RJ, Mathur AB. GNAS1 and PHD2 short-interfering RNA support bone regeneration in vitro and in an in vivo sheep model. Clin Orthop Relat Res. 2012;470(9):2541-53.

90. Jia S, Yang $X$, Song W, et al. Incorporation of osteogenic and angiogenic small interfering RNAs into chitosan sponge for bone tissue engineering. Int J Nanomedicine. 2014;9:5307-16.

91. Xu Y, Mirmalek-Sani SH, Yang X, Zhang J, Oreffo RO. The use of small interfering RNAs to inhibit adipocyte differentiation in human preadipocytes and fetal-femur-derived mesenchymal cells. Exp Cell Res. 2006;312(10):1856-64.

92. Kwong FN, Richardson SM, Evans $\mathrm{CH}$, Chordin knockdown enhances the osteogenic differentiation of human mesenchymal stem cells. Arthritis Res Ther. 2008;10(3):R65.

93. Chen E, Tang MK, Yao Y, et al. Silencing BRE expression in human umbilical cord perivascular (HUCPV) progenitor cells accelerates osteogenic and chondrogenic differentiation. PLoS One. 2013;8(7): e67896.

94. Zhang G, Guo B, Wu H, et al. A delivery system targeting bone formation surfaces to facilitate RNAi-based anabolic therapy. Nat Med. 2012;18(2):307-14.

95. Liang C, Guo B, Wu $\mathrm{H}$, et al. Aptamer-functionalized lipid nanoparticles targeting osteoblasts as a novel RNA interferencebased bone anabolic strategy. Nat Med. 2015;21(3):288-94.

96. Fulmer T. Curiously strong lipidoids. SciBX. 2010;3(2). Epub 2010 Jan 14. DOI:10.1038/scibx.2010.34

97. Ramasubramanian A, Jeeawoody S, Yang F. Gene delivery of osteoinductive signals to a human fetal osteoblast cell line induces cell death in a dose-dependent manner. Drug Deliv Transl Res. 2015:5(2):160-7.

98. Cho SW, Goldberg M, Son SM, et al. Lipid-like nanoparticles for small interfering RNA delivery to endothelial cells. Adv Funct Mater. 2009;19(19):3112-8.

99. El-Fiqi A, Kim TH, Kim M, et al. Capacity of mesoporous bioactive glass nanoparticles to deliver therapeutic molecules. Nanoscale. 2012;4(23):7475-88.

100. Jackson $A L$, Linsley PS. Recognizing and avoiding siRNA off-target effects for target identification and therapeutic application. Nat Rev Drug Discov. 2010;9(1):57-67.
101. Caffrey DR, Zhao J, Song Z, et al. siRNA off-target effects can be reduced at concentrations that match their individual potency. PLoS One. 2011;6(7):e21503.

102. Judge AD, Sood V, Shaw JR, Fang D, McClintock K, MacLachlan I. Sequence-dependent stimulation of the mammalian innate immune response by synthetic siRNA. Nat Biotechnol. 2005; 23(4):457-62.

103. Xavier JR, Thakur T, Desai $P$, et al. Bioactive nanoengineered hydrogels for bone tissue engineering: a growth-factor-free approach. ACS Nano. 2015;9(3):3109-18.

104. Fu S, Ni P, Wang B, et al. Injectable and thermo-sensitive PEGPCL-PEG copolymer/collagen/n-HA hydrogel composite for guided bone regeneration. Biomaterials. 2012;33(19):4801-9.

105. Mekhail M, Tabrizian M. Injectable chitosan-based scaffolds in regenerative medicine and their clinical translatability. Adv Healthc Mater. 2014;3(10):1529-45.

106. Nayef L, Mekhail M, Benameur L, Rendon JS, Hamdy R, Tabrizian M. A combinatorial approach towards achieving an injectable, selfcontained, phosphate-releasing scaffold for promoting biomineralization in critical size bone defects. Acta Biomater. 2016; 29:389-97.

107. Low SA, Yang J, Kopecek J. Bone-targeted acid-sensitive doxorubicin conjugate micelles as potential osteosarcoma therapeutics. Bioconjug Chem. 2014;25(11):2012-20.

108. Jiang T, Yu X, Carbone EJ, Nelson C, Kan HM, Lo KW. Poly aspartic acid peptide-linked PLGA based nanoscale particles: potential for bone-targeting drug delivery applications. Int J Pharm. 2014, 475(1-2):547-57.

109. Ossipov DA. Bisphosphonate-modified biomaterials for drug delivery and bone tissue engineering. Expert Opin Drug Deliv. 2015;12(9):1443-58

110. Hankenson KD, Dishowitz M, Gray C, Schenker M. Angiogenesis in bone regeneration. Injury. 2011;42(6):556-61.

111. Wan C, Allen TM, Cullis PR. Lipid nanoparticle delivery systems for siRNA-based therapeutics. Drug Deliv Transl Res. 2014;4(1): 74-83.

112. Fischer D, Li Y, Ahlemeyer B, Krieglstein J, Kissel T. In vitro cytotoxicity testing of polycations: influence of polymer structure on cell viability and hemolysis. Biomaterials. 2003, 24(7):1121-31

113. Xue HY, Liu S, Wong HL. Nanotoxicity: a key obstacle to clinical translation of siRNA-based nanomedicine. Nanomedicine (Lond). 2014;9(2):295-312.

114. Davis ME, Zuckerman JE, Choi CH, et al. Evidence of RNAi in humans from systemically administered siRNA via targeted nanoparticles. Nature. 2010;464(7291):1067-70.

115. Lappalainen K, Jääskeläinen I, Syrjänen K, Urtti A, Syrjänen S. Comparison of cell proliferation and toxicity assays using two cationic liposomes. Pharm Res. 1994;11(8):1127-31.

116. Xue HY, Guo P, Wen WC, Wong HL. Lipid-based nanocarriers for RNA delivery. Curr Pharm Des. 2015;21(22):3140-7.

117. Lv H, Zhang S, Wang B, Cui S, Yan J. Toxicity of cationic lipids and cationic polymers in gene delivery. J Control Release. 2006 114(1):100-9.

118. World of RNAi Therapeutics [Internet]. Available from: https://www. google.com/maps/d/viewer?mid=zr-Ht4ReTX3o.kFQo_CkRb9 AQ\&hl=en_US.

119. Aigner A. Gene silencing through RNA interference (RNAi) in vivo: strategies based on the direct application of siRNAs. J Biotechnol. 2006;124(1):12-25

120. Gondi CS, Rao JS. Concepts in in vivo siRNA delivery for cancer therapy. J Cell Physiol. 2009;220(2):285-91.

121. Grivas TB, Magnissalis EA. The use of twin-ring Ilizarov external fixator constructs: application and biomechanical proof-of principle with possible clinical indications. J Orthop Surg Res. $2011 ; 6: 41$ 